IJLRES - International Journal on Language, Research and Education Studies

ISSN: 2580-6777 (p); 2580-6785 (e)

DOI: 10.30575/2017/IJLRES-2018010401

Vol. 2, No. 1, 2018

Page: 1 - 18

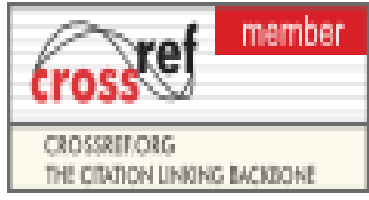

\title{
USE OF DIAGRAMS AS INSTRUCTIONAL AIDS IN TEACHING OF GEOMETRICAL CONCEPTS AT SECONDARY SCHOOL LEVEL
}

\author{
Muhammad Rizwan \\ Department of Education, University of Education Township Lahore, Pakistan \\ rizwan52400@gmail.co \\ Sobia Naseem \\ Department of Education, University of Education Township Lahore, Pakistan \\ srizwan.afaq@gmail.com \\ Syed Wasif Raza \\ Department of Education, University of the Punjab Lahore, Pakistan \\ swraza33@gmail.com
}

\begin{abstract}
Angle is a complex topic defined in a variety of contexts; some define angle to be as a pair of rays coming from a single point, as a rotation about a single point, or in a curve. Due to the multiple definitions of angle students get confused as to what an angle truly consists of. This study paid close attention to the misconceptions high school geometry students' hold about the concept of angle and how to help them gain a more conceptual understanding of this essential concept with the use of different Diagrams. The main idea behind the conduction of this study is to investigate the effect of use of diagrams as instructional aids on the conceptual understanding of angles. The study hypothesizes that angle can be learned using interactive Diagrams. The results of this study showed that diagrams which based on different A.V aids was shown to be more beneficial for the students who used to clear the concept of angles.
\end{abstract}

Keywords: Diagram, A.V Aids, Angle, Interactive Geometry Diagrams (IGD), Geometrical Understanding

\section{INTRODUCTION}

Geometry is also called the science of logical reasoning. In it, we approach everything with a question mark in our mind. As locked has said "Geometry is a way to settle in the mind a habit of reasoning ${ }^{1}$. Here the results are developed of reasoning. There are only a few premises on which we base our reasoning. The conclusions follow naturally from the given facts when logical reasoning is applied to the same. The reasoning in geometry is of peculiar kind and possesses a number of characteristics such as simplicity, accuracy, certainty of results, originality, similarity to the reasoning of life, and verification.

${ }^{1}$ Clements, D. H., \& Burns, B. A. (2000). Students' development of strategies for turns and angle measure. Educational Studies in Mathematics, hal. 41 31-45. 


\section{Muhammad Rizwan}

An important characteristic of geometry which distinguishes it from other subjects is its language and symbolism².

Geometry language and symbols cut short the lengthy statements and help the expression of ideas or things in the exact form. Geometry language is free from verbosity and helps in to the point, clear and exact expression of facts ${ }^{3}$. Geometry results in their symbolic form helps in solving numerous complicated problems. Most of the later progress in geometry depends heavily on the learner's ability to employ geometrical language and symbolism.

Geometry is a way to settle in a mind a habit of reasoning. It train or disciplines the mind. Due to its very nature it possesses, a real disciplinary values. It is exact, true and to the point knowledge and therefore creates a discipline in the mind. Its truths are definite and exact. It develops reasoning and thinking powers more and demand less from memory ${ }^{4}$. Reasoning in geometrical angles possesses certain characteristics which are suitable for the training of the learner's mind. If properly emphasized and streamlined, these characteristics are likely to develop the corresponding habits in the learner. There is a vast scope for simple reasoning in this subject. It teaches that definite facts are always expressed in a simple language and are always easily understandable ${ }^{5}$. The main thing is not the acquisition of knowledge but the acquirement of the power of acquiring knowledge.

A child before coming to school has already developed a system of concepts and peculiar way of perceiving and organizing the stimuli from his surroundings. During his stay in the school the new learning experiences extend, diversify and reorganize his conceptual system, his personality also change ${ }^{6}$. The different concepts can be learnt formally as well as informally. In the educational institutions, the learning is more formal

2 Close, G. S. (1982). Children's understanding of angle at primary/secondary transfer age. Master of science, Polytechnic of the South Bank, London, UK

${ }^{3}$ Euclid. (2014). Elements is by far the most famous mathematical work of classical... The Elements consists of thirteen books. Book 1 outlines the fundamental propositions of plane geometry

${ }^{4}$ Goos, M. (2004). Learning mathematics in a classroom community of inquiry. Journal for Research in Mathematics Education, 35 (4), 258-291.

5 Hollebrands, K., Laborde, C., \& StraBer, R. (2008). Technology and the learning of geometry at the secondary level. Research on Technology and the Teaching and Learning of Mathematics, 1, 155-205.

6 Bass, L. E., Charles, R. I., \& Johnson, A. (2004). Prentice Hall mathematics: Geometry. Upper Saddle River, NJ: Pearson Prentice Hall. 


\section{Use of Diagrams as Instructional Aids in Teaching of Geometrical Concepts at Secondary School Level}

DOI: 10.30575/2017/IJLRES-2018010401

than informal. The concepts are used to interpret the subject matter of different areas of knowledge. As we can safely say that all learning and knowledge is based upon the concepts, therefore, their importance is quite obvious?

Good result in teaching can be achieved if the students are correctly evaluated. The traditional style of teaching has badly failed to yield better result of teaching of angles. While researcher feels that if use of interactive diagrams technique, students gain conceptual understanding of angles ${ }^{8}$. The present study paid close attention to the misconceptions high school geometry students' hold about the concept of angle and how to help them gain a more conceptual understanding of this essential concept with the use of different Diagrams 9 .

\section{REVIEW LITERATURE}

\section{Teaching with Technology}

In the mathematics classrooms envisioned in NCTM's Principles and Standards, every student has access to technology to facilitate his or her mathematics learning under guidance of a skillful teacher"10. This would be ideal yet is often unsupported by individual schools due to constraints and other outside influences. Technology should not be used as a replacement for basic understandings and intuitions; rather, it can and should be used to foster those understandings and intuitions. Electronic technologies, calculators and computers, are essential tools for teaching, learning, and doing mathematics ${ }^{11}$. They furnish visual images of mathematical ideas, they facilitate organizing and analyzing data, and they compute efficiently and accurately. They can support investigation by students in every area of mathematics, including geometry, statistics, algebra, measurement, and number ${ }^{12}$.

Technology is expensive and takes more work for the teacher to learn and use

${ }^{7}$ Mitchelmore, M. (1997). Children's informal knowledge of physical angle situations. Learning and Instruction, 7 (1), 1-19.

${ }^{8}$ Mitchelmore, M., \& White, P. (1998). Development of angle concepts: A framework for research. Mathematics Education Research Journal, 10 (3), 4-27

9 Dr Mike Mitchelmore (2016). Development of angle concepts by progressive abstraction and generalization. Site Publisher: Macquarie University, Sydney Australia.

${ }^{10}$ Daniel J. Brahier. (2016). Teaching Secondary and Middle School Mathematics

${ }^{11}$ Bransford, J. D., Brown, A. L., \& Cocking, R. R. (1999). How people learn: Brain, mind, experience, and school. Washington DC: National Academy Press.

${ }^{12}$ Daniel J. Brahier. (2016). Teaching Secondary and Middle School Mathematics 


\section{Muhammad Rizwan}

the technology. Students can not only create diagrams and gain a deeper understanding through investigation but they often show different ways of thinking about mathematics with the use of technology not detected in normal classroom instruction ${ }^{13}$. The use of technology may be used to help students understand the concepts of angle by being able to manipulate the angle and see what does and does not change.

\section{Teaching with Interactive Geometry Diagrams (IGD)}

Students should be involved in their educational experience; they can gain a much deeper understanding of the concepts they are covering by doing the mathematics instead of simply watching teachers deliver the information to them. One good way to get students involved in their education and "doing" mathematics is with the use of diagrams. "Students' engagement with, and ownership of, abstract mathematical ideas can be fostered through diagram A.V aids ${ }^{14}$.

MacGregor and Thomas conducted a study in 2002 involving the value of IGD in the classroom. The study consisted of a control group with a lecture based learning environment and the other group of students explored the material through an investigation with IGD. Although the study concluded that "the instructional model where the teacher provided structure and directed the problem solving activities of the students resulted in learner outcomes characterized by greater understanding of the concepts and less frustration. Although the students were frustrated with the investigation, which the study reported might be due to the fact that the teacher and the students were uncomfortable with the pictures, they "expressed a sense of self-confidence and pleasure with their accomplishments" and learned a great deal of material with the IGD through discussion and exploration ${ }^{15}$.

\section{METHODOLOGY}

For collecting relevant information and data in order to arrive at reliable conclusions

${ }^{13}$ Daniel J. Brahier. (2016). Teaching Secondary and Middle School Mathematics

14 O Zaslavsky (2012). The Need for Proof and Proving: Mathematical and... - NYU Steinhardt.

${ }^{15}$ MacGregor, K. S. \& Thomas, R. W. (2002). Learning geometry dynamically: Teacher structure or facilitation NECC 2002: National Educational Computing Conference Proceedings (23rd, San Antonio, Texas, June 17-19, 2002), 1-14. 


\section{Use of Diagrams as Instructional Aids in Teaching of Geometrical Concepts at Secondary School Level}

DOI: 10.30575/2017/IJLRES-2018010401

certain method and procedure are required for all educational investigations. This chapter deals with the methodology and procedure adopted to conduct the study. The present study was under taken to find out the Secondary school students level of understanding in the field of geometrical angles. This study was experimental in nature. So the researcher adopted Experimental Research for his study. This section includes a description of selection of the subject, measuring instrument, construction of test, data collection procedure and data analysis.

\section{Selection of the Subject}

'Sixty' $10^{\text {th }}$ class students of Mathematics science group of Govt. H/s Baghbanpura Lahore, were selected as subjects of this study. A test was given to the subjects as Pre-Test. On the basis of test scores, pairs of subjects were made keeping in view their matching and or similar ability. Each member of each pair was included in a group A or group B randomly by using toss technique. Then group A and group B were selected as experimental group and control group through random assignment.

\section{Measuring Instrument}

Keeping in view the nature of the study, test was considered the best instrument for the collection of data. So a test was developed for students. There were 25 items for students in the test to identify the level of understanding or concept of the secondary school students of 'Government High School Baghbanpura' Lahore, in the field of Geometrical-Angles. Analysis of the content (subject matter) was made and then the test items were constructed accordingly. The test was classified into two different categories according to the nature of study. Test contains the following items

a) Multiple choice items

b) Short answer.

The percentage of Multiple Choice items was 64\% (16 items) and Short answer percentage was 36\% (9 items). These test items based upon the geometrical angels who described in rays, segments, triangles, polygons, and circle etc. 


\section{Muhammad Rizwan}

\section{FINDINGS AND DISCUSSION}

After the collection of data in the pre-test, instructional activity and post-test, the written responses from the pretest, instructional activity and post-test were then color coded to represent the subjects understanding of the concept being asked. The color coding was as follows: green was given to a response that was conceptually strong, yellow was given to a response that showed some conceptual understanding yet contained some misconceptions about the topic, and pink represented a lack of understanding of the topic being discussed. Once the responses were coded they were scored based on their color code.

Table 1. Pre-test (Control Group).

\begin{tabular}{|c|c|c|c|c|c|c|c|c|c|c|c|c|}
\hline & & & & Sh & tQue & ons & & & & & & \\
\hline Subject & Q.1 & Q.2 & Q.3 & Q.4 & Q.5 & Q.6 & Q.7 & Q.8 & Q.9 & $\begin{array}{l}\text { MCQ } \\
\text { s }\end{array}$ & $\begin{array}{l}\text { Total } \\
\text { Marks }\end{array}$ & $\begin{array}{l}\% \\
\text { age }\end{array}$ \\
\hline M. Muzammal & 2 & 2 & 1 & 2 & 1 & 1 & 2 & 0 & 1 & 8 & 20 & 59 \\
\hline M. Junaid & 2 & 2 & 2 & 1 & 1 & 1 & 1 & zero & Zero & 6 & 16 & 47 \\
\hline M. Zohaib & 1 & 2 & 1 & 1 & 1 & zero & N.A & zero & 2 & 6 & 14 & 41 \\
\hline Mudassar & 2 & 2 & 1 & 1 & 1 & 2 & 1 & 1 & 2 & 7 & 20 & 59 \\
\hline M. Zikrya & 1 & 1 & N.A & 1 & 2 & zero & 2 & zero & 1 & 4 & 12 & 35 \\
\hline M. Haroon & 2 & zero & 1 & 2 & 1 & 2 & 2 & 1 & Zero & 3 & 14 & 41 \\
\hline M. Atique & 1 & zero & zero & Zero & N.A & 2 & 2 & 1 & Zero & 4 & 10 & 29 \\
\hline M. Waheed & 2 & 1 & 2 & 2 & 1 & 1 & 1 & 1 & 1 & 5 & 17 & 50 \\
\hline Ali Rehman & 2 & 2 & 1 & Zero & 1 & zero & 2 & 2 & 1 & 6 & 17 & 50 \\
\hline M. Shakeel & 2 & 1 & 2 & 2 & 2 & 1 & zero & zero & N.A & 3 & 13 & 38 \\
\hline M. Umair & 1 & 1 & 1 & 1 & 2 & 1 & 1 & zero & Zero & 5 & 13 & 38 \\
\hline Shahzaib & 2 & 2 & 1 & 2 & 1 & 1 & 1 & 1 & 1 & 6 & 18 & 53 \\
\hline M. Zubair & 1 & 1 & 2 & 2 & 2 & zero & 1 & N.A & 2 & 3 & 14 & 41 \\
\hline M. Adil & 2 & 2 & 1 & 1 & 1 & N.A & 2 & zero & 1 & 4 & 14 & 41 \\
\hline M. Hamza & 2 & 2 & 1 & 2 & 1 & 1 & 2 & 1 & 2 & 6 & 20 & 59 \\
\hline M. Haseeb & 1 & 1 & 2 & Zero & Zero & zero & 2 & zero & Zero & 4 & 10 & 29 \\
\hline Abrar & 2 & 1 & 1 & Zero & 1 & zero & 1 & 1 & 1 & 5 & 13 & 38 \\
\hline Umer Ali & 1 & 2 & 2 & 2 & 1 & 1 & 2 & zero & N.A & 6 & 17 & 50 \\
\hline M. Zaraq & 2 & 2 & 2 & 1 & Zero & zero & zero & 1 & N.A & 1 & 9 & 26 \\
\hline M. Asad & zero & 1 & 1 & 1 & 1 & zero & zero & 1 & 1 & 3 & 9 & 26 \\
\hline M. Tayyab & 1 & zero & Zero & 1 & 2 & 1 & 1 & zero & 1 & 5 & 12 & 35 \\
\hline Shoaib Raza & 2 & 1 & 2 & 2 & 1 & zero & N.A & zero & 1 & 3 & 12 & 35 \\
\hline M. Saif & 1 & 2 & 2 & 1 & 1 & 2 & zero & 1 & zero & 6 & 16 & 47 \\
\hline Adnan Aslam & 2 & 2 & 1 & 1 & 1 & 1 & zero & 1 & 1 & 2 & 12 & 35 \\
\hline Mohsin Iqbal & 1 & 2 & 1 & 1 & Zero & zero & 1 & N.A & zero & 3 & 9 & 26 \\
\hline M. Fahid & 2 & 1 & 2 & 1 & 1 & 1 & zero & 1 & zero & 4 & 13 & 38 \\
\hline M. Awais & 2 & 2 & 1 & 2 & 2 & 2 & 1 & 1 & 1 & 5 & 19 & 56 \\
\hline Khawer Butt & 1 & 2 & Zero & Zero & 2 & 1 & 2 & 1 & 1 & 4 & 14 & 41 \\
\hline M. Azhar & 2 & 1 & 2 & 2 & 2 & 1 & zero & 1 & zero & 4 & 15 & 44 \\
\hline Khalid & 2 & 2 & 2 & 2 & 1 & 1 & 2 & N.A & 2 & 4 & 18 & 53 \\
\hline
\end{tabular}

Table 2. Post-test (Control Group). 


\begin{tabular}{|c|c|c|c|c|c|c|c|c|c|c|c|c|}
\hline \multicolumn{13}{|c|}{ Short Questions } \\
\hline Subject & Q.1 & Q.2 & Q.3 & Q.4 & Q.5 & Q.6 & Q.7 & Q.8 & Q.9 & MCQs & $\begin{array}{l}\text { Total } \\
\text { Marks }\end{array}$ & \%age \\
\hline M. Muzammal & 2 & 1 & 1 & 1 & 2 & 1 & 2 & zero & 1 & 8 & 19 & 56 \\
\hline M. Junaid & 2 & 2 & Zero & 1 & Zero & 1 & 1 & zero & zero & 6 & 13 & 38 \\
\hline M. Zohaib & 1 & 2 & 1 & 1 & 2 & zero & zero & zero & 2 & 6 & 15 & 44 \\
\hline Mudassar & 2 & 2 & 2 & 1 & 2 & 2 & 1 & 1 & 2 & 9 & 24 & 71 \\
\hline M. Zikrya & 1 & 1 & 2 & 2 & 2 & zero & 2 & zero & 2 & 6 & 17 & 50 \\
\hline M. Haroon & 2 & zero & Zero & 2 & 1 & 2 & 2 & 1 & 1 & 4 & 16 & 47 \\
\hline M. Atique & 1 & zero & 1 & Zero & 1 & 2 & 2 & 1 & zero & 6 & 14 & 41 \\
\hline M. Waheed & 1 & 1 & 1 & 2 & 1 & 2 & 1 & 1 & zero & 4 & 14 & 41 \\
\hline Ali Rehman & zero & 2 & 2 & 1 & 1 & zero & 2 & 2 & zero & 3 & 13 & 38 \\
\hline M. Shakeel & 2 & 1 & Zero & 1 & 2 & 1 & zero & 1 & zero & 4 & 12 & 35 \\
\hline M. Umair & zero & 1 & 1 & 1 & 2 & 1 & 1 & 1 & zero & 6 & 14 & 41 \\
\hline Shahzaib & zero & 2 & 1 & 2 & 1 & 1 & zero & 1 & 1 & 7 & 16 & 47 \\
\hline M. Zubair & 2 & 1 & 1 & 2 & 2 & 1 & 1 & zero & 2 & 6 & 18 & 53 \\
\hline M. Adil & zero & 2 & 1 & 1 & 2 & zero & 2 & zero & 2 & 5 & 15 & 44 \\
\hline M. Hamza & 1 & 2 & 2 & 2 & Zero & 1 & zero & 1 & 2 & 5 & 16 & 47 \\
\hline M. Haseeb & 1 & 1 & 1 & Zero & 1 & zero & 2 & 1 & 1 & 6 & 14 & 41 \\
\hline Abrar & 2 & 1 & 2 & Zero & 1 & zero & 1 & 1 & 1 & 4 & 13 & 38 \\
\hline Umer Ali & 1 & 2 & 2 & 2 & 1 & 1 & 2 & zero & zero & 6 & 17 & 50 \\
\hline M. Zaraq & 2 & 2 & 1 & 1 & Zero & zero & zero & 1 & zero & 2 & 09 & 26 \\
\hline M. Asad & zero & 1 & 1 & 1 & 1 & zero & zero & 1 & 1 & 3 & 09 & 26 \\
\hline M. Tayyab & zero & zero & Zero & 1 & 1 & 2 & 1 & zero & 2 & 5 & 12 & 35 \\
\hline Shoaib Raza & 1 & 1 & 2 & 2 & Zero & zero & zero & 1 & 2 & 3 & 12 & 35 \\
\hline M. Saif & zero & 2 & 1 & Zero & 1 & 2 & 1 & 1 & zero & 5 & 13 & 38 \\
\hline Adnan Aslam & 1 & 2 & 1 & 1 & 1 & 1 & zero & 1 & zero & 2 & 10 & 29 \\
\hline Mohsin Iqbal & 1 & 2 & 1 & Zero & Zero & 1 & 1 & 1 & zero & 5 & 12 & 35 \\
\hline M. Fahid & 1 & 1 & 1 & 1 & 1 & 1 & zero & 1 & zero & 5 & 12 & 35 \\
\hline M. Awais & zero & 2 & Zero & 1 & 2 & 1 & 1 & 1 & 2 & 6 & 16 & 47 \\
\hline Khawer Butt & 1 & 2 & 1 & Zero & 1 & 1 & 2 & 1 & 2 & 6 & 17 & 50 \\
\hline M. Azhar & 2 & 1 & 1 & 2 & 2 & 1 & 0 & 1 & 0 & 4 & 15 & 44 \\
\hline Khalid & zero & 2 & 1 & 2 & Zero & 1 & 2 & zero & 2 & 6 & 16 & 47 \\
\hline
\end{tabular}

Table 3. Pre-test (Experimental Group).

\begin{tabular}{lllllllllllll}
\hline \multicolumn{10}{c}{ Short Questions } & \multicolumn{1}{c}{ (10 } \\
\hline Subject & Q.1 & Q.2 & Q.3 & Q.4 & Q.5 & Q.6 & Q.7 & Q.8 & Q.9 & MCQs & $\begin{array}{l}\text { Total } \\
\text { Marks }\end{array}$ & \%age \\
\hline M. Sawal & zero & 2 & 1 & 2 & zero & 1 & 1 & zero & 1 & 10 & 18 & 53 \\
M. Umar & Zero & 2 & 1 & 1 & 2 & 1 & zero & 1 & zero & 08 & 16 & 47 \\
M.Usman & 1 & 1 & 2 & 1 & 2 & 1 & zero & 2 & 1 & 11 & 22 & 65 \\
M.Usama & 1 & 1 & 2 & Zero & 1 & zero & 1 & zero & 2 & 7 & 15 & 44 \\
Zubair & zero & 2 & 2 & Zero & 1 & 2 & zero & 1 & 1 & 9 & 18 & 53 \\
Waseem & 1 & 2 & 1 & Zero & 1 & 2 & zero & 2 & 1 & 8 & 18 & 53 \\
Hamza & zero & zero & Zero & Zero & 1 & 1 & 2 & zero & 1 & 6 & 11 & 32 \\
Bilal & 1 & 1 & 2 & Zero & 1 & 1 & 1 & zero & zero & 6 & 13 & 38 \\
Ali Sher & 1 & zero & 1 & 1 & zero & 2 & zero & zero & 1 & 5 & 11 & 32 \\
M. Azhar & zero & 2 & Zero & 1 & 1 & 1 & 1 & zero & 1 & 7 & 14 & 41 \\
Junaid & 1 & 1 & 1 & Zero & 1 & 1 & zero & 1 & 2 & 4 & 11 & 32 \\
Rehman & zero & zero & 2 & Zero & 1 & 2 & zero & 1 & zero & 6 & 12 & 35 \\
Shehbaz & zero & 1 & Zero & 1 & 1 & 1 & 1 & 1 & 2 & 9 & 17 & 50 \\
Ahsan Ali & zero & 1 & Zero & 1 & 1 & 1 & 1 & 1 & 1 & 5 & 12 & 35 \\
M. Afzal & zero & zero & 1 & 1 & 1 & 1 & 2 & zero & 2 & 6 & 14 & 41 \\
M. Khan & 1 & 2 & Zero & 1 & 1 & 2 & 1 & 1 & 1 & 3 & 13 & 38 \\
M. Saeed & zero & 1 & 2 & Zero & 2 & 1 & 1 & 1 & 2 & 5 & 15 & 44 \\
Ahmad & zero & zero & 1 & Zero & 2 & 1 & 1 & 2 & 1 & 5 & 13 & 38 \\
Tahir & zero & 1 & 1 & 2 & 1 & 1 & zero & zero & zero & 2 & 08 & 24 \\
Younas & 1 & zero & 1 & Zero & 1 & 1 & 1 & zero & zero & 6 & 11 & 32 \\
\hline
\end{tabular}




\begin{tabular}{|c|c|c|c|c|c|c|c|c|c|c|c|c|}
\hline Ali Raza & zero & zero & 1 & 2 & 1 & zero & zero & zero & 2 & 4 & 10 & 29 \\
\hline Naeem & zero & 1 & Zero & 2 & 1 & zero & 2 & zero & zero & 7 & 13 & 38 \\
\hline Daniyal & 1 & 1 & 2 & 1 & 1 & zero & 1 & zero & 2 & 3 & 12 & 35 \\
\hline Zeshan & zero & 1 & 2 & Zero & zero & zero & zero & 1 & 1 & 4 & 09 & 26 \\
\hline M. Tariq & zero & 1 & Zero & 1 & 1 & 1 & zero & zero & 1 & 5 & 10 & 29 \\
\hline Fahad & 1 & 2 & 1 & Zero & zero & 2 & zero & 1 & zero & 7 & 14 & 41 \\
\hline M. Ali & 1 & zero & Zero & 2 & 1 & 1 & zero & zero & 1 & 4 & 10 & 29 \\
\hline Dilawar & zero & 2 & 1 & 2 & 1 & 1 & 2 & 1 & zero & 8 & 18 & 53 \\
\hline Arsalan & zero & 1 & 2 & Zero & 1 & zero & 1 & zero & 1 & 4 & 10 & 29 \\
\hline $\begin{array}{l}\text { Asad } \\
\text { Hussain }\end{array}$ & zero & 1 & 1 & 1 & 1 & 1 & 1 & 2 & zero & 3 & 11 & 32 \\
\hline
\end{tabular}

Table 4. Post-test (Experimental Group).

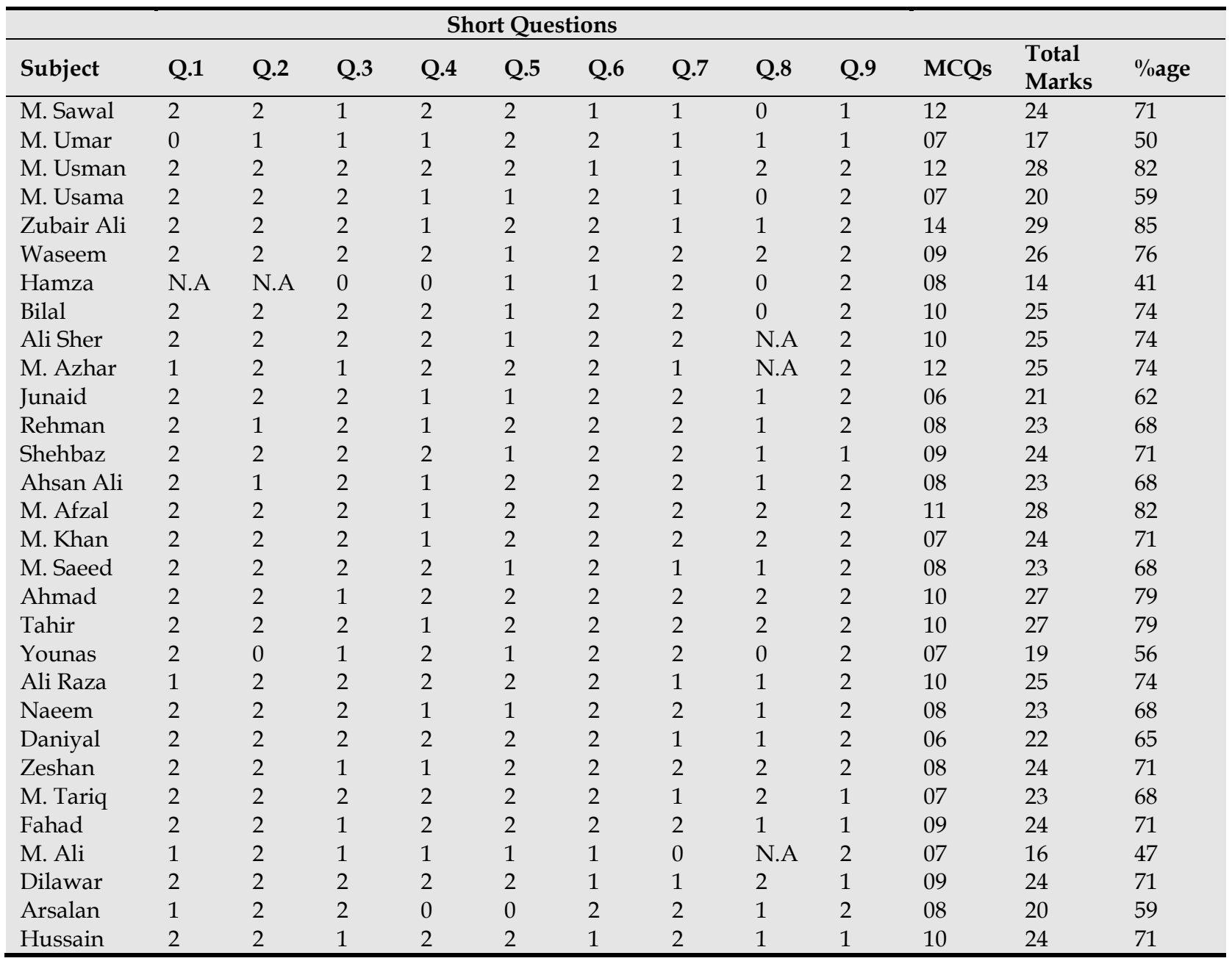

The green code received two points, the yellow code received one point and the pink code received no points; this action was taken so the researcher could analyze the students' gain scores. The coding was also used to help discover patterns of misconceptions held by the students throughout the study. After the researcher identified the common misconceptions the students possessed before the study by analyzing the coding of the pre-test, the researcher started considering categories or 


\section{Use of Diagrams as Instructional Aids in Teaching of Geometrical Concepts at

DOI: 10.30575/2017/IJLRES-2018010401

levels of some sort to demonstrate students' conceptual understanding of angle. While studying the data, the researcher needed to decide whether categorization or levels of understanding would best fit this study; the researcher considered these possible categorizations and levels described below in order to make her decision:

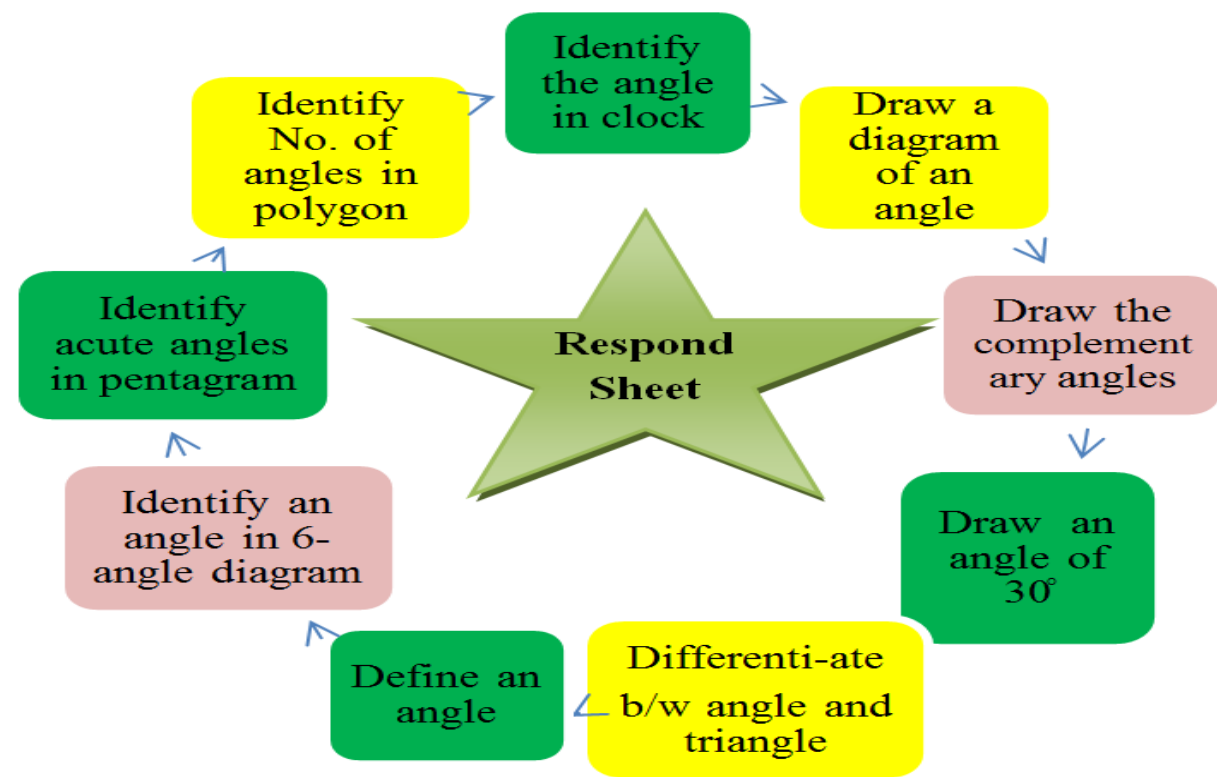

a) Piaget's stage theory of development: "They defined three stages of development between the ages of two and 11 years. At state 1, children can only recognize familiar objects, not shapes. At Stage 2 (pre-operatory level), they grasp topological (inside-outside, open-close) as well as rectilinear and curvilinear relations, but not metric or Euclidean relations. At the final stage (operatory level), children start to apply metric and Euclidean ones" 16.

b) van Hiele's levels: Similar to the Piaget's stages yet "progressing from one stage to the next depends more on the teaching method adopted than on age, and this makes the geometry-related experiences of the child a determining factor" ${ }^{\prime \prime}$.

c) Mitchelmore \& White (1998) categories, which can be found in figure 1. After consideration, the author chose to use a modification of the Mitchelmore \& White

16 Munier, V., \& Merle, H. (2009). Interdisciplinary mathematics - physics approaches to teaching the concept of angle in elementary school. International Journal of Science Education, 31 (14), 1857-1895

${ }_{17}$ Munier, V., \& Merle, H. (2009). Interdisciplinary mathematics - physics approaches to teaching the concept of angle in elementary school. International Journal of Science Education, 31 (14), 1857-1895 


\section{Muhammad Rizwan}

categories due to the fact that one cannot say if students' understands angle better using any of the multiple definitions. Since there are multiple definitions, multiple categories are needed to assess students' conceptual understanding of angle ${ }^{18}$.

\section{Interpretations of Data}

The study was conducted to identify the use of diagrams as instructional aids in teaching of geometrical angles at secondary school level. For this purpose an objective type test was taken from the students. The data was analyzed by calculating the percentage and difference of pre and posttest of the students. From the table 5, the mean of control group pre-test and post-test is $14.33 \& 14.47$ and its standard deviation is 3.346 \& 3.060 similarly the mean of experimental group pre-test and post-test is $13.27 \& 23.33$ and its standard deviation is $3.373 \& 3.491$, so the average score of control group test is less than experimental group test. In the comparison of control group and experimental group in pretest, the results shown that mean value and standard deviation are slightly higher than experimental group. This indicates the equivalent mental attitude towards geometrical angles without using diagrams as instructional aids among students. In contrast to pre-test, post -test results of experimental group shows tremendous results/remarked difference/huge variation than control group. Experimental group has greater value of mean (23.23) as compare to control group (14.47) while standard deviation value of experimental group exceeds from 0.431 units than control group. Similarly standard error mean values of experimental group are greater than control group in both pre and post -test.

Table 5. Group statistics.

\begin{tabular}{|c|c|c|c|c|c|}
\hline & Group & $\mathrm{N}$ & Mean & Std. Deviation & $\begin{array}{c}\text { Std. } \\
\text { Error } \\
\text { Mean }\end{array}$ \\
\hline \multirow[t]{2}{*}{$\begin{array}{c}\text { Pre-test } \\
\text { Marks }\end{array}$} & $\begin{array}{l}\text { Controlled } \\
\text { Group }\end{array}$ & 30 & 14.33 & 3.346 & .611 \\
\hline & $\begin{array}{l}\text { Experimental } \\
\text { Group }\end{array}$ & 30 & 13.27 & 3.373 & .616 \\
\hline $\begin{array}{c}\text { Post-test } \\
\text { Marks }\end{array}$ & $\begin{array}{l}\text { Controlled } \\
\text { Group }\end{array}$ & 30 & 14.47 & 3.060 & .559 \\
\hline
\end{tabular}

${ }^{18}$ Mitchelmore, M., \& White, P. (1998). Development of angle concepts: A framework for research. Mathematics Education Research Journal, 10 (3), 4-27 
Use of Diagrams as Instructional Aids in Teaching of Geometrical Concepts at Secondary School Level

DOI: 10.30575/2017/IJLRES-2018010401

\begin{tabular}{ccccc}
\hline $\begin{array}{c}\text { Experimental } \\
\text { Group }\end{array}$ & 30 & 23.23 & 3.491 & .637 \\
\hline
\end{tabular}

Table 6. Independent Samples Test

\begin{tabular}{|c|c|c|c|c|c|c|c|c|}
\hline \multicolumn{9}{|c|}{ t-test for Equality of Means } \\
\hline & & \multirow[b]{2}{*}{$\mathrm{t}$} & \multirow[b]{2}{*}{$\mathrm{df}$} & \multirow[b]{2}{*}{$\begin{array}{l}\text { Sig. (p- } \\
\text { value) }\end{array}$} & \multirow[b]{2}{*}{$\begin{array}{l}\text { Mean } \\
\text { Diff. }\end{array}$} & \multirow[b]{2}{*}{$\begin{array}{l}\text { Std. } \\
\text { Error } \\
\text { Diff. }\end{array}$} & \multicolumn{2}{|c|}{$\begin{array}{l}95 \% \text { Confidence } \\
\text { Interval of the } \\
\text { Difference }\end{array}$} \\
\hline & & & & & & & Lower & Upper \\
\hline $\begin{array}{l}\text { Pre-test } \\
\text { Marks }\end{array}$ & $\begin{array}{l}\text { Equal variance } \\
\text { assumed }\end{array}$ & 1.230 & 58 & .224 & 1.067 & .867 & -.670 & 2.803 \\
\hline $\begin{array}{l}\text { Post-test } \\
\text { Marks }\end{array}$ & $\begin{array}{l}\text { Equal variance } \\
\text { assumed }\end{array}$ & -10.345 & 58 & .000 & -8.767 & .847 & -10.463 & -7.070 \\
\hline
\end{tabular}

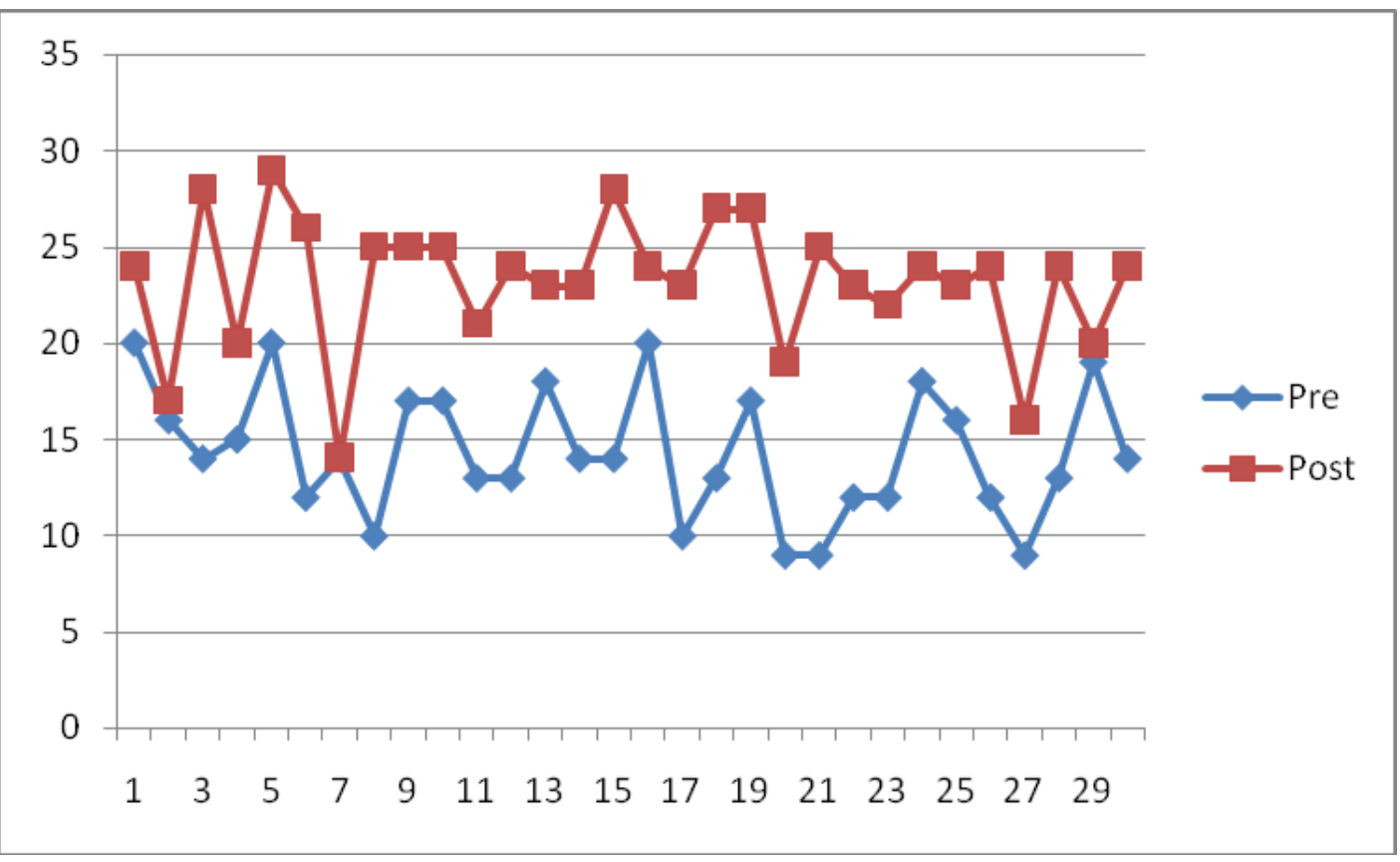

Figure 2. T-test of pre and post-test

\section{Comparison between Pre and Post-Test Results of Control Group}

Pre and post-test of control group shows random results because some pupils have higher and some have lower percentages in posttest than in pre-test. Lower percentages may be due to lack of attention and non-serious behavior towards demonstration so that they don't have much difference in \%ages.

Table 7. Comparison between percentages of pre and post -test of Control group.

\begin{tabular}{lll}
\hline \multirow{2}{*}{ Subject } & Pre-test & Post-test \\
\cline { 2 - 3 } & \%age & \%age \\
\hline M. Muzammal & 56 & 59 \\
M. Junaid & 38 & 47 \\
M. Zohaib & 44 & 41 \\
Mudassar & 71 & 59 \\
\hline
\end{tabular}




\begin{tabular}{lll}
\hline \multirow{2}{*}{ Subject } & Pre-test & Post-test \\
\cline { 2 - 3 } \%age & \%age \\
\hline M. Zikrya & 50 & 35 \\
M. Haroon & 47 & 41 \\
M. Atique & 41 & 29 \\
M. Waheed & 41 & 50 \\
Ali Rehman & 38 & 50 \\
M. Shakeel & 35 & 38 \\
M. Umair & 41 & 38 \\
Shahzaib & 47 & 53 \\
M. Zubair & 53 & 41 \\
M. Adil & 44 & 41 \\
M. Hamza & 47 & 59 \\
M. Haseeb & 41 & 29 \\
Abrar & 38 & 38 \\
Umer Ali & 50 & 50 \\
M. Zaraq & 26 & 26 \\
M. Asad & 26 & 26 \\
M. Tayyab & 35 & 35 \\
Shoaib Raza & 35 & 35 \\
M. Saif & 38 & 47 \\
Adnan Aslam & 29 & 35 \\
Mohsin Iqbal & 35 & 26 \\
M. Fahid & 35 & 38 \\
M. Awais & 47 & 56 \\
Khawer Butt & 50 & 41 \\
M. Azhar & 44 & 53 \\
Khalid & 47 &
\end{tabular}

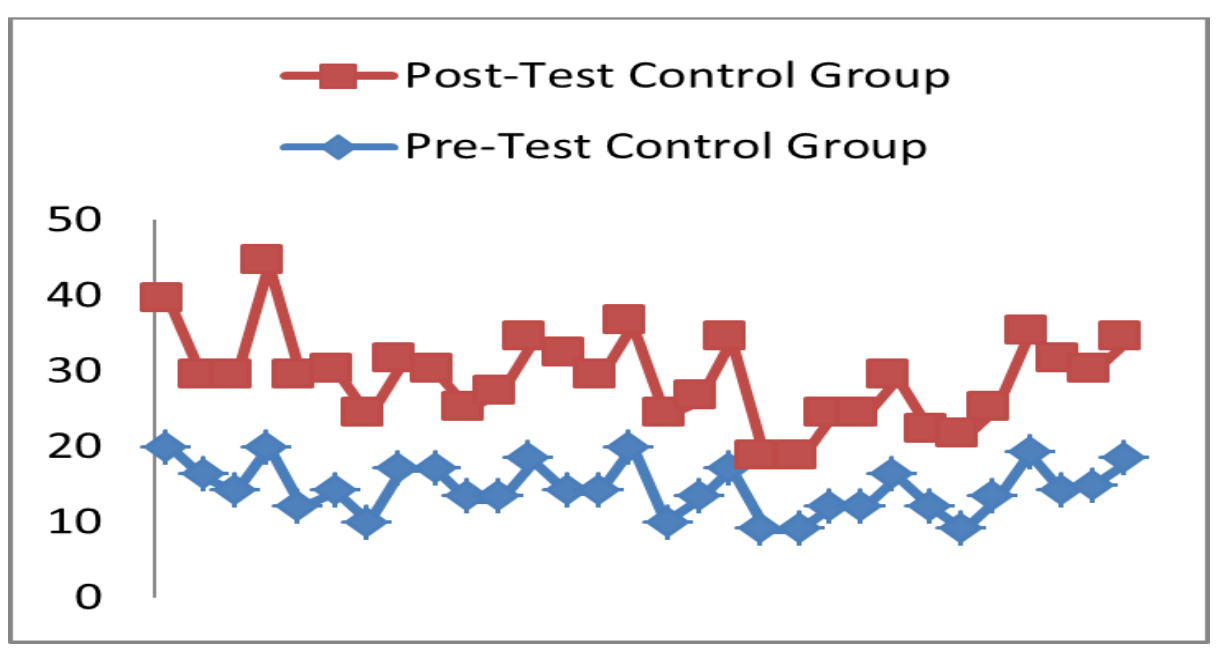

Figure 3. Comparison between percentages of pre and post -test of Control group.

\section{Comparison between Pre and Post-Test Results of Experimental Group}

It is clear from table results that experimental group students have shown remark 


\section{Use of Diagrams as Instructional Aids in Teaching of Geometrical Concepts at Secondary School Level}

DOI: 10.30575/2017/IJLRES-2018010401

difference towards conceptual understanding of geometrical angles with and without using diagrams as instructional aids in pre and posttest. They proved that learning with using diagrams is better for them and it played a greater role in developing concepts/enhancing their cognition level for geometrical angles. Students express their views that diagram made a clear concept and help for easy to understand than without diagrams.

Table 8. Comparison between Percentages of pre and post-test of Experimental group.

\begin{tabular}{|c|c|c|}
\hline \multirow{2}{*}{ subject } & Pre-test & Post-test \\
\hline & \%age & \%age \\
\hline M. Sawal & 53 & 71 \\
\hline M. Umar & 47 & 50 \\
\hline M. Usman & 65 & 82 \\
\hline M. Usama & 44 & 59 \\
\hline Zubair Ali & 53 & 85 \\
\hline M. Waseem & 53 & 76 \\
\hline Ali Hamza & 32 & 41 \\
\hline Bilal Tariq & 38 & 74 \\
\hline Ali Sher & 32 & 74 \\
\hline M. Azhar & 41 & 74 \\
\hline Junaid Iqbal & 32 & 62 \\
\hline M. Rehman & 35 & 68 \\
\hline M. Shehbaz & 50 & 71 \\
\hline Ahsan Ali & 35 & 68 \\
\hline M. Af NGzal & 41 & 82 \\
\hline M. Khan & 38 & 71 \\
\hline M. Saeed & 44 & 68 \\
\hline Ali Ahmad & 38 & 79 \\
\hline Tahir & 24 & 79 \\
\hline Umer Younas & 32 & 56 \\
\hline Ali Raza & 29 & 74 \\
\hline Naeem Amir & 38 & 68 \\
\hline Daniyal & 35 & 65 \\
\hline Zeshan & 26 & 71 \\
\hline M. Tariq & 29 & 68 \\
\hline Fahad & 41 & 71 \\
\hline M. Ali & 29 & 47 \\
\hline Dilawar & 53 & 71 \\
\hline Arsalan & 29 & 59 \\
\hline Asad Hussain & 32 & 71 \\
\hline
\end{tabular}




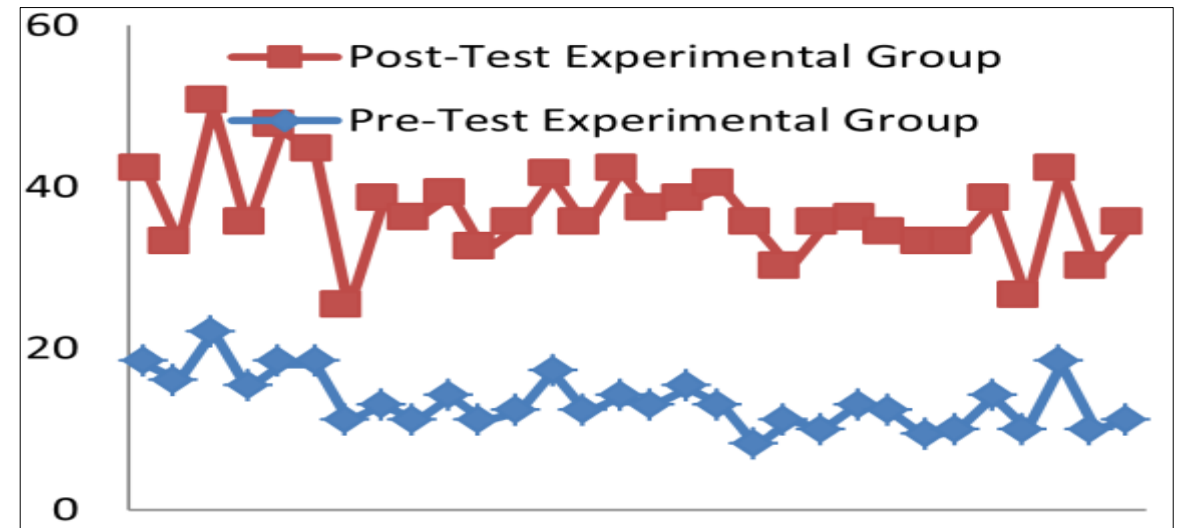

Figure 4. Comparison between Percentages of pre and post-test of Experimental group.

\section{Comparison between Pre-test of Experimental and Control Group}

In the case of comparison made between pre-test of control and experimental groups, there is no much difference in percentages of pupils. It means both groups have almost same level of understanding the lecture without using diagrams as instructional aids. Minor up and down values can be ignored due to individual intellectual level.

Table 9. Comparison between Pre-test of Experimental and Control Group.

\begin{tabular}{llll}
\hline Control group & Pre-test & Experimental group & Pre-test \\
\hline Subject & \%age & Subject & \%age \\
\hline M. Muzammal & 56 & M. Sawal & 53 \\
M. Junaid & 38 & M. Umar & 47 \\
M. Zohaib & 44 & M. Usman & 65 \\
Mudassar & 71 & M. Usama & 44 \\
M. Zikrya & 50 & Zubair Ali & 53 \\
M. Haroon & 47 & M. Waseem & 53 \\
M. Atique & 41 & Ali Hamza & 32 \\
M. Waheed & 41 & Bilal Tariq & 38 \\
Ali Rehman & 38 & Ali Sher & 32 \\
M. Shakeel & 35 & M. Azhar & 41 \\
M. Umair & 41 & Junaid Iqbal & 32 \\
Shahzaib & 47 & M. Rehman & 35 \\
M. Zubair & 53 & M. Shehbaz & 50 \\
M. Adil & 44 & Ahsan Ali & 35 \\
M. Hamza & 47 & M. Af NGzal & 41 \\
M. Haseeb & 41 & M. Khan & 38 \\
Abrar & 38 & M. Saeed & 44 \\
Umer Ali & 50 & Ali Ahmad & 38 \\
M. Zaraq & 26 & Tahir & 24 \\
M. Asad & 26 & Umer Younas & 32 \\
M. Tayyab & 35 & Ali Raza & 29 \\
\hline
\end{tabular}


DOI: 10.30575/2017/IJLRES-2018010401

\begin{tabular}{llll}
\hline Control group & Pre-test & Experimental group & Pre-test \\
\hline Subject & \%age & Subject & \%age \\
\hline Shoaib Raza & 35 & Naeem Amir & 38 \\
M. Saif & 38 & Daniyal & 35 \\
Adnan Aslam & 29 & Zeshan & 26 \\
Mohsin Iqbal & 35 & M. Tariq & 29 \\
M. Fahid & 35 & Fahad & 41 \\
M. Awais & 47 & M. Ali & 29 \\
Khawer Butt & 50 & Dilawar & 53 \\
M. Azhar & 44 & Arsalan & 29 \\
Khalid & 47 & Asad Hussain & 32 \\
\hline
\end{tabular}

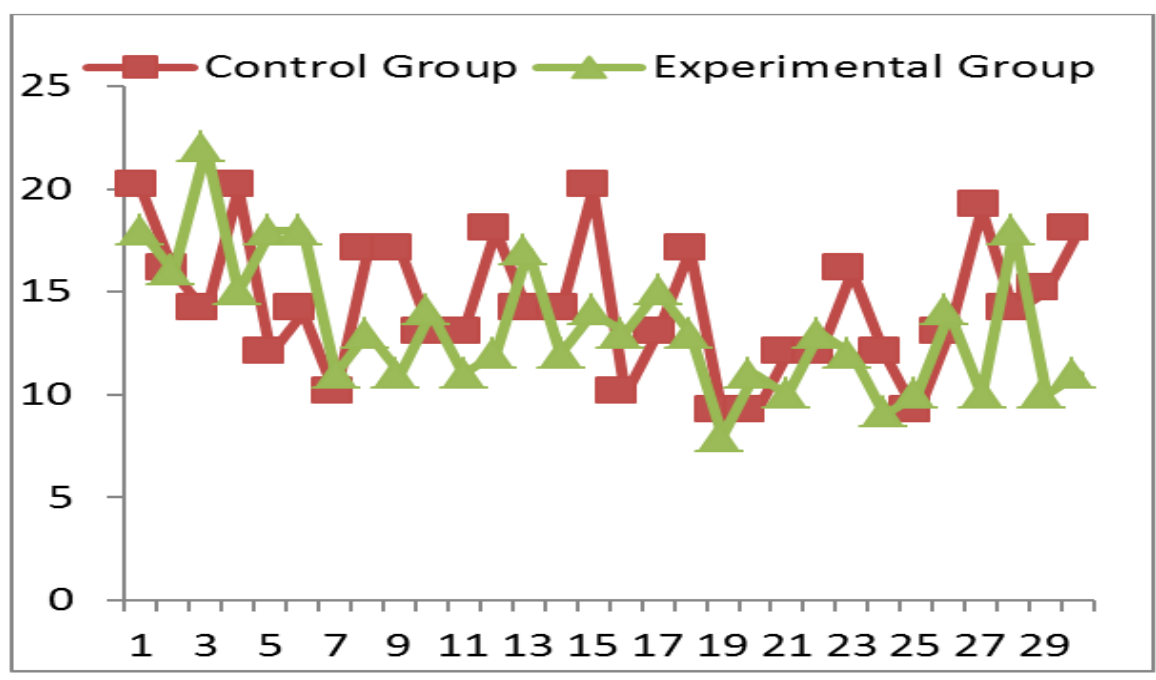

Figure 5. Comparison between Pre-test of Experimental and Control Group.

\section{Comparison between Post-test of Control and Experimental Group}

The use of instructional aids promotes learning interest and cognition level. It was clearly proved by the graph of comparison of post-test of control and experimental group that explain the higher values of percentages of experimental group due to use of diagrams as instructional aids. Table 6 also satisfies this statement effectively.

Table 10. Comparison between Post-test of Control Group and Experimental Group.

\begin{tabular}{llll}
\hline Control Group & Post-test & $\begin{array}{l}\text { Experimental } \\
\text { group }\end{array}$ & Post-test \\
\hline Subject & \%age & Subject & \%age \\
\hline M. Muzammal & 59 & M. Sawal & 71 \\
M. Junaid & 47 & M. Umar & 50 \\
M. Zohaib & 41 & M. Usman & 82 \\
Mudassar & 59 & M. Usama & 59 \\
M. Zikrya & 35 & Zubair Ali & 85 \\
\hline
\end{tabular}




\begin{tabular}{llll}
\hline Control Group & Post-test & $\begin{array}{l}\text { Experimental } \\
\text { group }\end{array}$ & Post-test \\
\hline Subject & \%age & Subject & \%age \\
\hline M. Haroon & 41 & M. Waseem & 76 \\
M. Atique & 29 & Ali Hamza & 41 \\
M. Waheed & 50 & Bilal Tariq & 74 \\
Ali Rehman & 50 & Ali Sher & 74 \\
M. Shakeel & 38 & M. Azhar & 74 \\
M. Umair & 38 & Junaid Iqbal & 62 \\
Shahzaib & 53 & M. Rehman & 68 \\
M. Zubair & 41 & M. Shehbaz & 71 \\
M. Adil & 41 & Ahsan Ali & 68 \\
M. Hamza & 59 & M. Af NGzal & 82 \\
M. Haseeb & 29 & M. Khan & 71 \\
Abrar & 38 & M. Saeed & 68 \\
Umer Ali & 50 & Ali Ahmad & 79 \\
M. Zaraq & 26 & Tahir & 79 \\
M. Asad & 26 & Umer Younas & 56 \\
M. Tayyab & 35 & Ali Raza & 74 \\
Shoaib Raza & 35 & Naeem Amir & 68 \\
M. Saif & 47 & Daniyal & 65 \\
Adnan Aslam & 35 & Zeshan & 71 \\
Mohsin Iqbal & 26 & M. Tariq & 68 \\
M. Fahid & 38 & Fahad & 71 \\
M. Awais & 56 & M. Ali & 47 \\
Khawer Butt & 41 & Dilawar & 71 \\
M. Azhar & 44 & Arsalan & 59 \\
Khalid & 53 & Asad Hussain & 71 \\
\hline
\end{tabular}

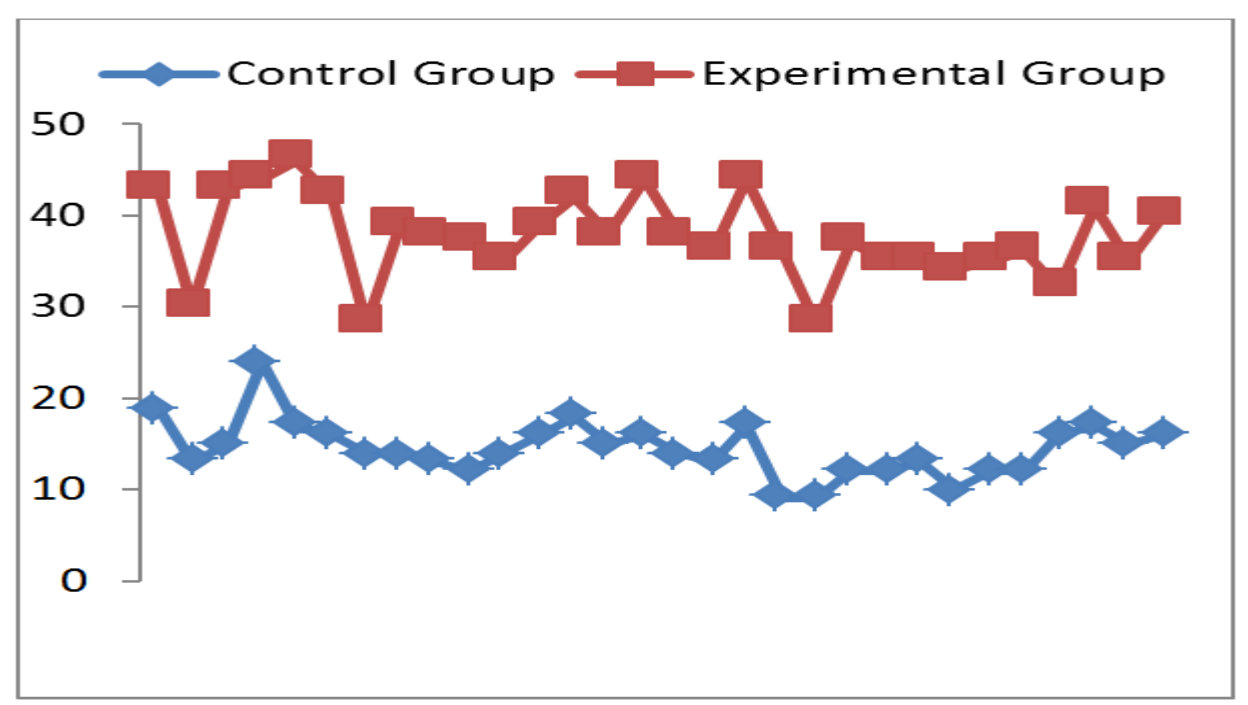

Figure 6. Comparison between Post-test of Control Group and Experimental Group. 


\section{Use of Diagrams as Instructional Aids in Teaching of Geometrical Concepts at Secondary School Level}

DOI: 10.30575/2017/IJLRES-2018010401

\section{CONCLUSION}

The importance of IGD A.V aids in the mathematics classroom has been investigated through a variety of venues about a variety of topics throughout mathematics education research. This study is designed to use this research and expand upon it while investigating the importance of angle comprehension in the geometry classroom. Concerns about angle comprehension were discussed through different studies and the mathematics curriculum; angle needs to be researched further to comprehend the level of misunderstanding which students hold when it comes to understanding the use of angle. The introduction of Interactive Geometry Diagrams (IGD) into the geometry classroom has evolved and can now involve students in a more active learning environment.

It is found experimentally that $92 \%$ students attempt correct response during test. In multiple choice items the percentage of students who gave correct response was $96 \%$ after the post test. In short answer type question the percentage of students who gave correct answer were $90 \%$. 4\% students got zero marks in multiple choice questions. $10 \%$ students got zero marks in short answers type questions. In pretest the Mean value of the correct response was "14.33" and standard deviation was "3.346". In posttest the Mean value of the correct response was "23.33" and standard deviation was "3.491". Finally the researcher was collected the significance $(\mathrm{P})$ value 0.0001 .

This study is not looking to see if the diagram is important, this has already been established. The question to answer is not if the diagram is important but how the use of the diagram is important and beneficial for students' conceptual understanding of angle.

\section{BIBILIOGRAPHY}

Bass, L. E., Charles, R. I., \& Johnson, A. (2004). Prentice Hall mathematics: Geometry. Upper Saddle River, NJ: Pearson Prentice Hall.

Bransford, J. D., Brown, A. L., \& Cocking, R. R. (1999). How people learn: Brain, mind, experience, and school. Washington DC: National Academy Press.

Clements, D. H., \& Burns, B. A. (2000). Students' development of strategies for turns and angle measure. Educational Studies in Mathematics, 41, 31-45.

Close, G. S. (1982). Children's understanding of angle at primary/secondary transfer age. Master of science, Polytechnic of the South Bank, London, UK.

Daniel J. B. (2016). Teaching Secondary and Middle School Mathematics 
Euclid. (2014). Elements is by far the most famous mathematical work of classical... The Elements consists of thirteen books. Book 1 outlines the fundamental propositions of plane geometry.

Goos, M. (2004). Learning mathematics in a classroom community of inquiry. Journal for Research in Mathematics Education, 35 (4), 258-291.

Hollebrands, K., Laborde, C., \& StraBer, R. (2008). Technology and the learning of geometry at the secondary level. Research on Technology and the Teaching and Learning of Mathematics, 1, 155-205.

Keiser, J. M. (2004). Struggles with developing the concept of angles: Comparing sixthgrade students' discourse to the history of the angle concept. Mathematical Thinking and Learning, 6 (3), 285-306.

MacGregor, K. S. \& Thomas, R. W. (2002). Learning geometry dynamically: Teacher structure or facilitation NECC 2002: National Educational Computing Conference Proceedings (23rd, San Antonio, Texas, June 17-19, 2002), 1-14.

Mike Mitchelmore (2016). Development of angle concepts by progressive abstraction and generalization. Site Publisher: Macquarie University, Sydney Australia.

Mitchelmore, M. (1997). Children's informal knowledge of physical angle situations. Learning and Instruction, 7 (1), 1-19.

Mitchelmore, M., \& White, P. (1998). Development of angle concepts: A framework for research. Mathematics Education Research Journal, 10 (3), 4-27

Munier, V., \& Merle, H. (2009). Interdisciplinary mathematics - physics approaches to teaching the concept of angle in elementary school. International Journal of Science Education, 31 (14), 1857-1895

Zaslavsky,O (2012). The Need for Proof and Proving: Mathematical and... - NYU Steinhardt. 